2018-04

\title{
Top ten concerns burdening people with cancer: perceptions of patients with cancer and the nurses caring for them
}

\section{Endacott, Ruth}

http://hdl.handle.net/10026.1/10834

\author{
10.1016/j.ejon.2018.02.004 \\ European Journal of Oncology Nursing \\ Elsevier
}

All content in PEARL is protected by copyright law. Author manuscripts are made available in accordance with publisher policies. Please cite only the published version using the details provided on the item record or document. In the absence of an open licence (e.g. Creative Commons), permissions for further reuse of content should be sought from the publisher or author. 


\section{Top ten concerns burdening people with cancer: perceptions of patients with cancer and the nurses caring for them}

This is an accepted manuscript of an article published by Elsevier in European Journal of Oncology

Nursing in February 2018.

Keith SJ Mitchell, RN

Clinical Project Lead: "Living with and Beyond a Cancer Diagnosis" and "End of Life" Royal Devon \& Exeter NHS Foundation Trust, Barrack Rd, Exeter, Devon EX2 5DW Phone: 01392406513

Email: Keithmitchell1@nhs.net

Sarah Delfont, Diploma in Counselling for Grief, Loss and Life-threatening Illness

Lead Oncology Support Specialist

FORCE Cancer Charity, Barrack Rd, Exeter, Devon EX2 5DW

Phone: 01392406169

Email: $\underline{\text { Sarah.delfont@nhs.net }}$

Maria Lucinda Bracey, RN,

Macmillan Clinical Project Nurse

Royal Devon \& Exeter NHS Foundation Trust, Barrack Rd, Exeter, Devon EX2 5DW

Phone: 01392406577

Email: maria.bracey@nhs.net

Ruth Endacott (corresponding author), RN, PhD

Professor of Clinical Nursing and Director, Plymouth University/Royal Devon and Exeter Hospital Clinical School,

University of Plymouth, Faculty of Health and Human Sciences, Plymouth PL4 8AA

Phone: 07816636259

Email: ruth.endacott@plymouth.ac.uk

ORCID ID: 0000000243524600 


\title{
Top ten concerns burdening people with cancer: perceptions of patients with cancer
}

\section{and the nurses caring for them}

\begin{abstract}
Purpose We examined the concerns that nurses perceive patients to have, whether these are congruent with patients' concerns and whether they vary according to cancer site. We also examined Distress Thermometer scores according to cancer site.
\end{abstract}

Method A cross-sectional survey design: (i) secondary analysis of an existing Holistic Needs Assessment (HNA) and Distress Thermometer (DT) dataset was used, (ii) a survey of specialist nurse teams to identify their perceptions of patient concerns. Data collected between January 2015 and June 2016 from the HNA database for one NHS Trust in England $(\mathrm{n}=1233$ patients). Specialist nurse teams for breast, colorectal, gynaecology, skin and urology cancers identified the concerns that they perceived their patients would report.

Results The HNA showed high internal consistency (Cronbach's alpha 0.86). Across the five cancer sites, nurses identified between 3 and 6 of the top ten concerns (TTC) expressed by patients, with wide variation across sites. Nine of the TTC were significantly associated $(p<0.05)$ with a specific cancer site. The breast and gynaecological cancer groups both recorded significantly higher median Distress Thermometer scores than the urology, skin and colorectal cancer groups (Kruskall-Wallis $\left.\chi^{2}(4, \mathrm{n}=1228) 186.695, p=<.01\right)$.

Conclusions: One of the aims of the eHNA is to enable service delivery appropriate to patient needs. Our findings suggest that this will only be achieved if eHNA is examined, and services developed, by individual cancer site. The misconception of patient needs by specialist nurses underscores the importance of review of information provided by patients during consultations. 


\section{Background}

The vision for living with and beyond a cancer diagnosis involves a cultural shift to focus on recovery, health and wellbeing, with care based on a model of empowerment (Department of Health, Macmillan Cancer Support and NHS Improvement 2013). Empowerment is enacted through an emphasis on information about services that patients may access, rather than referrals, allowing patients to make an informed choice. However, this model also emphasises the importance of a mutually agreed care plan, jointly owned by the patient and health professionals.

A number of health needs have been identified by people living with cancer with findings from a systematic review 15 years ago revealing that physical, emotional, psychological, social, practical, and financial needs were highly prevalent domains of need (Australian National Breast Cancer Centre and National Cancer Control Initiative 2003). More recent studies support this finding, although patient and physician identification of needs is not always congruent (Baile et al 2011). The ongoing needs of an individual with cancer can be easily misconstrued, which may lead to delays in appropriate interventions and referrals (Bestall et al 2004) with unmet health needs in newly diagnosed older people found to range from 15-93\% (Puts et al 2012).

A number of measures have been used to capture the needs of people with cancer, including the Patient Concerns Inventory (Wells et al 2015a), Distress Thermometer and Problem List (DT\&PL) (National Comprehensive Cancer Network 2016), the Supportive Care Needs Survey (SCNS-SF34) (Boyes et al 2009) and the Holistic Needs Assessment (IPSOS Mori Social Research Institute 2013). The Distress Thermometer has revealed differences between cancer sites (Zabora et al 2001) and studies have investigated illnesses such as depression (Krebber et al 2014) across cancer sites. However, studies exploring met and unmet needs of people with cancer have often tended to focus on single sites, such as colorectal cancer or 
breast cancer; in a qualitative study, interviews were conducted with head and neck and breast cancer survivors but researchers did not compare findings by cancer site (Lubberding et al 2015).in a study across cancer sites, use of the electronic version of the HNA (eHNA) resulted in more than half of participants reporting its' utility in discussing concerns with their health care team (Ipsos Mori 2015).

In the UK, the National Cancer Survivorship Initiative aims to offer all people with cancer the opportunity to complete a holistic needs assessment (HNA), focusing on a wide range of factors that may impact on the wellbeing of the patient (Department of Health 2012a, National Cancer Action Team 2013). The underpinning ethos of the 48-item HNA is not to identify hierarchies of need for the individual but to ensure that all needs are captured (Snowden and Fleming 2015). However, it is also important to understand what needs are of most importance, in order to inform service planning, hence there has been an emphasis on identifying the top ten concerns (TTC) for people with cancer (Kuczkowska et al 2015). Whilst this has been undertaken across all cancers, there has been no detailed analysis of differences by cancer site.

The Holistic Needs assessment (HNA) has a two-fold purpose: to help those with cancer better express their needs and to enable health care professionals to plan care, with targeted, bespoke support. The concerns documented in the Holistic Needs Assessment have been grouped into five domains: physical, practical, social, emotional and spiritual (Snowden \& Fleming 2015). The aim of this study was to compare the primary concerns as expressed by people with cancer and as perceived by the nurses who care for them and to examine whether these vary according to cancer site.

\section{Objectives}

1. To compare the concerns expressed by patients and perceived by nurses 
2. To examine concerns and distress, as measured by the distress thermometer, by cancer site

3. To compare concerns against the national survey findings

\section{Design and Methods}

A survey design was used comprising:

1. Cross-sectional patient survey: using the eHNA and the Distress Thermometer,

2. Staff survey: specialist nurse teams identified the top ten concerns that they perceived their patients to have

\section{Instruments}

The HNA consist of 48 needs statements (e.g. 'sleep problems', 'unable to express feelings') with a scale rated from 0 (no problem) to 10 and is completed shortly after dagnosis. The electronic version (eHNA), developed by MacMillan Cancer Support UK (IPSOS Mori Social Research Institute 2013), is completed via a tablet with the completed assessment uploaded to a secure website for viewing by the individual's care team. The eHNA has been validated with a sample of 5421 using Rasch analysis and factor analysis, and has demonstrated internal consistency and construct validity, in terms of the construct of holistic needs (Snowden \& Fleming 2015).

The Distress Thermometer (DT), developed by the National Comprehensive Cancer Network in the United States, is regarded as the forerunner to the HNA and has been used extensively to assess the psychological needs of people affected by cancer (Holland and Bultz 2007). Although the HNA also contains psychological need statements, it is common for DT and HNA to be used together for patient assessment as it provides a global self-assessment of distress. 
Five specialist nurse teams, responsible for breast, colorectal, gynaecological, skin and urological cancers, were asked to list the top ten concerns that they perceived their patients would report, without reference to the eHNA. The teams for each cancer site (e.g. the specialist breast cancer nurses) developed the list by a process of consensus within their specialist team.

We conducted a secondary analysis of data collected between Jan 2015 and June 2016 from the eHNA/DT online database for one NHS Trust. The eHNA and DT were completed by patients shortly after diagnosis, in line with its' use in other studies (IPSOS Mori Social Research Institute 2013).

Data analysis

Descriptive statistics, including cross tabulations, were used to identify frequencies and associations in the data. Cronbach's alpha was used to determine reliability. Chi square was used to examine associations between top ten concerns statements and cancer site; Kruskal Wallis was used to examine differences between DT scores by cancer site.

\section{Results}

A total of 1233 patients completed the eHNA between January 2015 and June 2016 and five specialist nurse teams identified patient concerns. Patients with breast $(n=282)$ and gynaecological $(n=79)$ cancers were all female and urological cancer patients $(n=447)$ were all male. Colorectal and skin cancer patients were $49.6 \%$ and $48 \%$ female.

The internal consistency for the eHNA was high (Cronbach alpha .861); this is similar to the agreement achieved in the eHNA validation study (0.87) (Snowden \& Fleming 2015). Some items identified by our participants were ranked in the top ten concerns identified in the national study (Kuczkowska et al 2015) but eight additional concerns were identified by our participants (see Table 1). 


\section{INSERT TABLE 1 HERE}

The top ten concerns identified in the Macmillan study (Kuczkowska et al 2015) were identified as a concern for between 2.7 and $29.8 \%$ of the patients included in our study (see Table 2). Nine of the ten individual statements were also significantly associated $(p<0.05)$ with a specific cancer site (see Table 2). The three top concerns (worry/fear/anxiety, tiredness/exhaustion/fatigue and sleep problems/nightmares) were common across all five cancer sites.

\section{INSERT TABLE 2 HERE}

The median DT score was zero for colorectal and skin cancer (IQR 4 and 2 respectively) (see Table 2). Kruskal-Wallis test revealed a statistically significant difference in Distress Thermometer score across the five cancer sites, $\chi^{2}(4, \mathrm{n}=1228) 186.69, p=<.01$ (see Table 2). The breast cancer and gynaecological cancer groups both recorded significantly higher median scores than the urology, skin and colorectal cancer groups. These differences remained significant following Bonferroni adjustment.

Across the five cancer sites, nurses identified between 3 and 6 of the TTC reported by patients; of note the breast cancer and gynaecological cancer teams only identified three of the ten concerns identified by patients (see Table 3).

\section{INSERT TABLE 3 HERE}

\section{Discussion}

Our data identified three notable findings: variation in concerns and distress by cancer site; differences between nurses and patients; number of needs that may not have been revealed without the HNA. 
Variation in the TTC expressed by patients with different cancers emphasises the need to reconsider service planning; our findings indicate that 'one size does not fit all'. Differences by cancer site have been identified in previous studies, for example, prevalence of depression (Krebber et al 2014), information needs and information seeking (Tan et al 2015). The specialist nurse teams also identified different perceptions of patient need according to cancer site. Regardless of the above, it is also pertinent to remember that the HNA was not originally designed to be used as a ranking exercise - the 'holistic' ethos means that all needs identified by the individual patient should be taken into account when planning care (Snowden \& Fleming 2015). However, in order to plan services, some measure of the extent to which needs prevail across patients is important; the HNA appears to suit this purpose.

Psychological counselling has become a key part of cancer treatment, reflecting concerns about the impact of changing mood states on longer term psychological health for people with cancer. For this study distress was measured using the Distress Thermometer, previously credited with detecting hidden distress (Biddle et al 2016). An espoused benefit of using an objective measure of distress, rather than relying on clinician judgment, is that referral to psychological services is more likely to be based on need (Vodermaier et al 2009) however there is no evidence that this benefit has been realised. Further, on implementing the Distress Thermometer with haematological cancer patients receiving chemotherapy, Child (2010) recommended that its' primary use should be to facilitate conversation. Our findings highlight differences in median distress scores according to cancer site, similar to those identified by Zabora et al (2001), indicating that particular emphasis should be placed on initiating conversations about psychological wellbeing in patients with breast cancer or gynaecological cancer.

Differences between nurse perceptions and patients' reporting of needs seem to indicate a longer term view taken by nurses, for example 'fears about recurrence' and 'long term 
treatment side effects'. These needs also do not appear in the list of 48 HNA items. This difference in perspective has been reported previously; Baile and colleagues (2011) identified poor concordance between patient and physician reporting of patient concerns, albeit in patients with cancer attending a palliative care clinic. By contrast, a recent Delphi study was conducted in the UK with 50 oncology nurses and 18 patients, to identify research priorities for oncology nursing. Patients and nurses were in agreement about the need for further research into the management of anxiety and uncertainty following cancer treatment (Cox et al 2017). In the United States, the Institute of Medicine outlined four essential components of cancer survivorship: prevention, surveillance, intervention and co-ordination (Hewitt et al 2006); patients completing the HNA are perhaps more likely to be focused on the immediate impact of the diagnosis, rather than the longer term implications. This may in part explain the difference in perspectives. However the over-riding message arising from these differences is that nurses and doctors have an inaccurate perception of the concerns of people with cancer. Holistic Needs Assessment is promoted as a 'process of gathering and discussing information with the patient' (Snowden \& White 2014, p5) and has the potential to trigger conversation between the patient and clinicians (Samarasinghe \& Wiles 2012). Our findings indicate that HNA is assessed but does not form the basis of discussion with patients. This is similar to findings in the UK National Cancer Patient survey 2011-12, in which only $24 \%$ of patients reported that they were offered a written assessment and care plan (Department of Health 2012b). Reluctance to produce a care plan has also been attributed to lack of confidence (Wells et al 2015b). The National Cancer Patient Experience Survey (NCPES) in England has consistently demonstrated that patients with cancer who have access to a Clinical Nurse Specialist (CNS), report better experiences and understanding of the disease (https://www.quality-health.co.uk/resources/surveys/national-cancer-experience-survey) and are more positive about almost every aspect of their care (Griffiths et al 2013). Further, 
patients' experience of care coordination and emotional support was better in NHS Trusts with a greater number of specialist nurses (Griffiths et al 2013). However, our findings indicate that specialist nurses have some improvements to make regarding use of the eHNA, completed by patients, to inform care planning.

Most of the concerns may not have been revealed by patients during routine clinical consultations, emphasising the value of patients completing the HNA; Taylor and colleagues (2012) identified positive feedback from patients following the introduction of HNA but difficulties have also been identified with integrating HNA into routine care, including lack of communication skills and confidence (Young et al 2014) and problems with data connectivity across the NHS in the UK (IPSOS Mori Social Research Institute 2013). A survey of nurses and allied health professionals $(n=74)$ caring for people with head and neck cancer found that the greatest barrier to completion of the HNA was lack of time, followed by lack of private space, lack of training and lack of appropriate services to refer on to (Wells et al 2015b). The electronic HNA appears to be more successful than earlier paper-based assessments, with greater numbers of assessments completed (IPSOS Mori Social Research Institute 2013). However, clinicians also have to be mindful that if patients perceive eHNA as a tick box exercise, it can lead to an increase in anxiety if identified needs are not then discussed (Snowden et al 2012).

\section{Limitations}

This study was conducted in a single centre, albeit with patients from different cancer teams, hence the extent to which these results would be replicated in other centres is not known. Patients completing the eHNA were responding to a pre-determined list of concerns. Whilst these have strong validity, there is no indication whether patients would like to add new items; hence we were not able to ascertain whether these were similar to the need perceived by nurses. There is a free text box in the eHNA to identify any other concerns but this was 
rarely used; this may mean that the list of eHNA statements allowed respondents to articulate their needs. However, this may also be a limitation of electronic version, completed via a tablet.

\section{Conclusions}

One of the original aims of the eHNA is to enable delivery of services appropriate to patient needs. Our findings suggest that this will only be achieved if eHNA is examined, and services developed, by cancer site, rather than across services. The extent of misconception of patient needs, even within specialist teams, underscores the importance of using the eHNA assessment to inform care planning for the individual patient.

\section{Conflict of Interest}

None

\section{Data statement}

No data sets have been specified by the author for the following reason:

The data that has been used is confidential 


\section{References}

Baile W.F., Palmer J.L., Bruera E., Parker P.A. (2011) Assessment of palliative care cancer patients' most important concerns. Supportive Care in Cancer 19(4): 475-481.

Bestall J.C. , Ahmed N., Ahmedzai S.H., Payne S.A., Noble B., Clark D. (2004) Access and referral to specialist palliative care: Patients' and professionals' experiences. International Journal of Palliative Nursing 10: 381-389.

Biddle L., Paramasivan S., Harris S., Campbell R., Brennan J., Hollingworth W. (2016) Patients' and clinicians' experiences of holistic needs assessment using a cancer distress thermometer and problem list: a qualitative study. European Journal of Oncology Nursing 23: $59-65$

Boyes A., Girgis A., Lecathelinais C. (2009) Brief assessment of adult cancer patients' perceived needs: development and validation of the 34-item Supportive Care Needs Survey (SCNS-SF34). Journal of Evaluation in Clinical Practice, 15(4): 602-606

Child S. (2010) A tool to measure psychological distress during chemotherapy. Cancer Nursing Practice 9(6): 33-8

Cox A., Arber A., Gallagher A., Mackenzie M., Ream E. (2017) Establishing Priorities for Oncology Nursing Research: Nurse and Patient Collaboration. Oncology Nursing Forum 44: 192-203.

Department of Health (2012a) National Cancer Survivorship Initiative Vision DH, London

Department of Health (2012b) National Cancer Patient Experience Survey 2011/12 national report $\mathrm{DH}$, London

Department of Health, Macmillan Cancer Support \& NHS Improvement (2013) Living with and beyond cancer: taking action to improve outcomes $\mathrm{DH}$, London 
Griffiths P., Simon M., Richardson A., Corner J. (2013) Is a larger specialist nurse workforce in cancer care associated with better patient experience? Cross-sectional study. Journal of Health Services Research and Policy 18 (Suppl 1), 39-46

Hewitt M., Greenfield S., Stovall S. (2006). From cancer patient to cancer survivor: Lost in transition. Washington, DC: National Academies Press.

Holland J.C., Bultz B.D. (2007) The NCCN guideline for distress management: a case for making distress the sixth vital sign. J Natl Compr Cancer Netw 5:3-7

IPSOS Mori Social Research Institute (2013) Evaluation of the Electronic Holistic Needs Assessment Baseline Report. Available at: https://www.macmillan.org.uk/_images/e-hnaevaluation-report-executive-summary_tcm9-283675.pdf (accessed 15/02/2018)

Krebber A.M., Buffart L.M., Kleijn G., Riepma I.C., Bree R., Leemans C.R., Becker A., Brug J., Straten A., Cuijpers P., Verdonck-de Leeuw I.M. (2014) Prevalence of depression in cancer patients: a meta-analysis of diagnostic interviews and self-report instruments. Psycho-Oncology. 23(2):121-30.

Kuczkowska K., Watson A., Brittle A. (2015) Using Electronic Holistic Needs Assessment (eHNA) data to explore the needs of people with cancer and how they are addressed European Journal Of Cancer Care 24 (s1): 75.

Lubberding S., Uden-Kraan C. F., Te Velde E. A., Cuijpers P., Leemans C. R., Verdonck-de Leeuw I. M. (2015) Improving access to supportive cancer care through an eHealth application: a qualitative needs assessment among cancer survivors. Journal of Clinical Nursing 24(9-10): 1367-1379.

National Cancer Action Team (2013) Holistic needs assessment for people with cancer. A practical guide for healthcare professionals. 
National Comprehensive Cancer Network (2016) NCCN Distress Thermometer and Problem List for Patients. Available at:

https://www.nccn.org/patients/resources/life_with_cancer/pdf/nccn_distress_thermometer. pdf (accessed 15/02/2018)

Puts M.T.E., Papoutsis A., Springall E., Tourangeau A.E. (2012) A systematic review of unmet needs of newly diagnosed older cancer patients undergoing active cancer treatment. Supportive Care in Cancer. 20(7): 1377-94

Samarasinghe B.S.W., Wiles L. (2012) Meeting patient needs with risk-stratified colorectal cancer follow-up. Gastrointestinal Nursing 10(3): 37-43.

Snowden A., Fleming M. (2015) Validation of the electronic Holistic Needs Assessment Springer Plus 4: 623.

Snowden A., White C. (2014) Assessment and care planning for cancer survivors: a concise evidence review. Available at: http://www.macmillan.org.uk/_images/assessment-andcare-planning-for-cancer-survivors_tcm9-297790.pdf Accessed 15/02/2018.

Snowden A., White C.A., Christie Z., Murray E., McGowan C., Scott R. (2012) Helping the clinician help me: towards listening in cancer care. Br J Nurs 21(10): S18-26. doi: 10.12968/bjon.2012.21.Sup10.S18

Tan A.S., Nagler R.H., Hornik R.C., DeMichele A. (2015) Evolving information needs among colon, breast, and prostate cancer survivors: results from a longitudinal mixedeffects analysis. Cancer Epidemiology and Prevention Biomarkers. 2015 May 15:cebp0041.

Taylor C., Cummings R., McGilly C. (2012) Holistic needs assessment following colorectal cancer treatment. Gastrointestinal Nursing 10(9): 42-49. 
Vodermaier A., Linden W., Siu C. (2009) Screening for emotional distress in cancer patients: a systematic review of assessment instruments. Journal of National Cancer Institute 101: $1464-1488$

Wells M., Cunningham M., Lang H., Swartzman S., Philp J., Taylor L., Thomson J. (2015a). Distress, concerns and unmet needs in survivors of head and neck cancer: a cross-sectional survey. European Journal of Cancer Care, 24(5):748-760.

Wells M., Semple C.J., Lane C. (2015b) A national survey of healthcare professionals' views on models of follow-up, holistic needs assessment and survivorship care for patients with head and neck cancer. European Journal of Cancer Care. 24(6):873-83.

Young J., Cund A., Renshaw M., Quigley A., Snowden A. (2014) Improving the care of cancer patients: holistic needs assessment. British Journal of Nursing Oncology Supplement, 23(16): S20-S24

Zabora J., Brintzenhofeszoc K., Curbow B., Hooker C., Piantadosi S. (2001) the prevalence of psychological distress by cancer site. Psycho-Oncology 10: 19-28 
Table 1 Concerns identified in our data but not listed in the top ten concerns national survey (Kuczkowska et al 2015)

\begin{tabular}{|l|l|}
\hline Concern & Prevalence \\
\hline Bowel changes or constipation & $17.1 \%$ \\
\hline Partner & $15.1 \%$ \\
\hline Nervousness & $14.0 \%$ \\
\hline Unable to make plans & $12.2 \%$ \\
\hline Getting to places & $10.7 \%$ \\
\hline Panicky & $10.4 \%$ \\
\hline Children & $9.8 \%$ \\
\hline People close to you & $9.6 \%$ \\
\hline
\end{tabular}


Table 2 Comparison between generic top ten concerns and concerns by cancer site

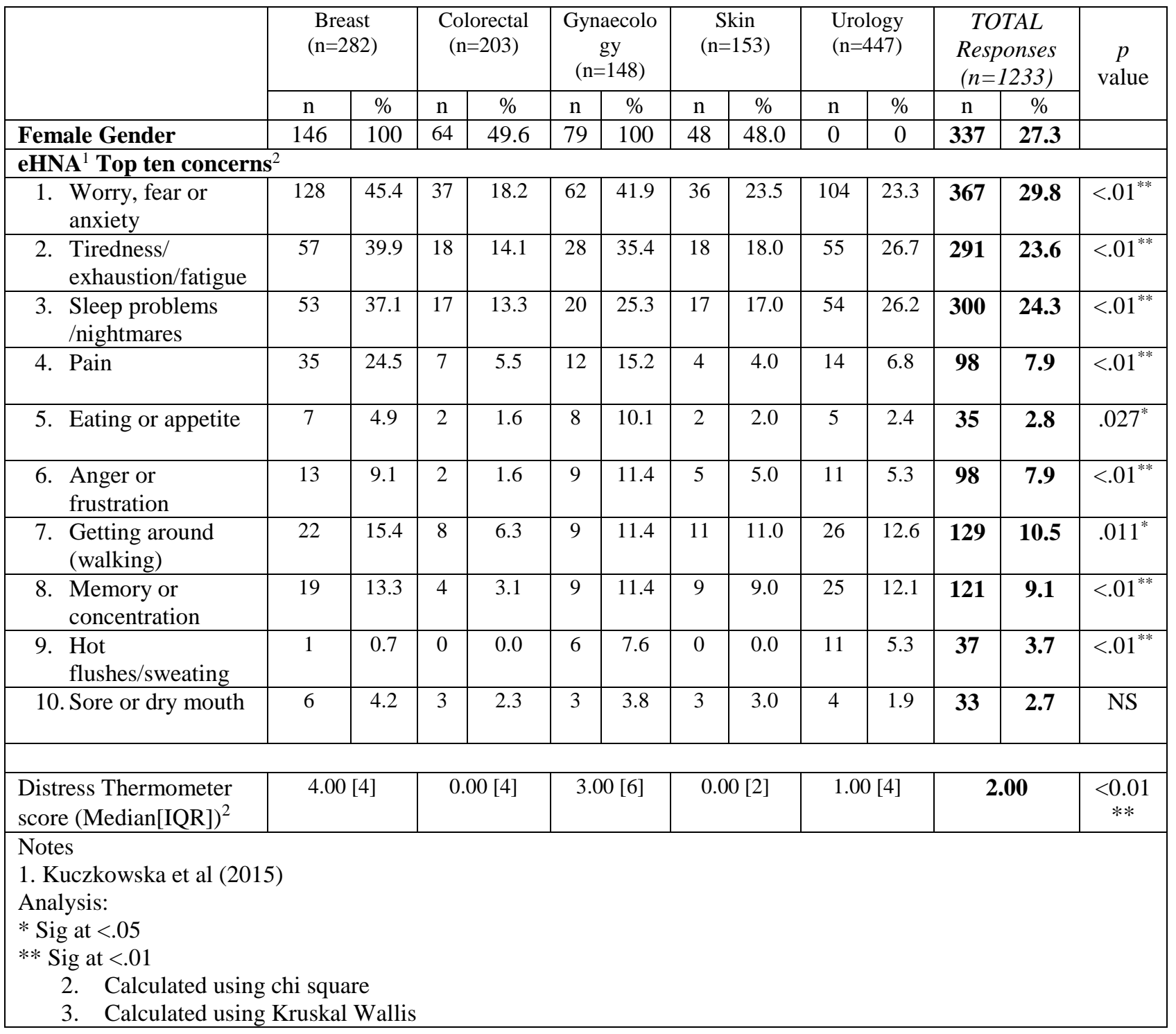


Table 3 Comparison between nurse and patient concerns by cancer site

\begin{tabular}{|c|c|c|}
\hline \multirow[t]{2}{*}{ Patient top ten concerns from eHNA } & \multicolumn{2}{|c|}{$\begin{array}{l}\text { Nurse specialist team perceptions of patient } \\
\text { concerns }\end{array}$} \\
\hline & Same & Different concerns \\
\hline \multicolumn{3}{|l|}{ Urology cancer ( $n=206$ patients) } \\
\hline 1. Fatigue/tiredness & $\checkmark$ & \multirow{10}{*}{$\begin{array}{l}\text { Unable to make plans } \\
\text { People close to you } \\
\text { Restlessness/unable to } \\
\text { relax } \\
\text { Nausea/vomiting }\end{array}$} \\
\hline 2. Sexual functioning & $\checkmark$ & \\
\hline 3. Poor sleep & $\checkmark$ & \\
\hline 4. Partner & & \\
\hline 5. Bowel changes/constipation or diarrhoea & $\checkmark$ & \\
\hline 6. Fears/worries & $\checkmark$ & \\
\hline 7. Changes in urination & & \\
\hline 8. Loss of interest in usual activity & & \\
\hline 9. Walking/getting around & $\checkmark$ & \\
\hline 10. weakness & & \\
\hline \multicolumn{3}{|l|}{ Colorectal cancer (n=128 patients) } \\
\hline 1. Fears/worries & & \multirow{10}{*}{$\begin{array}{l}\text { Finances and work } \\
\text { Diet } \\
\text { Driving } \\
\text { Unable to make plans } \\
\text { If stoma is temporary } \\
\text { or permanent }\end{array}$} \\
\hline 2. Bowel changes/constipation or diarrhoea & $\checkmark$ & \\
\hline 3. Fatigue/tiredness & $\checkmark$ & \\
\hline 4. Poor sleep & $\checkmark$ & \\
\hline 5. Partner & & \\
\hline 6. People close to you & & \\
\hline 7. Weight loss & & \\
\hline 8. Getting to places & & \\
\hline 9. Walking/getting around & & \\
\hline 10. Pain/changes in sensation & & \\
\hline \multicolumn{3}{|l|}{ Breast cancer ( $n=143$ patients) } \\
\hline 1. Fatigue/tiredness & $\checkmark$ & \multirow{10}{*}{$\begin{array}{l}\text { Finances } \\
\text { Body image issues } \\
\text { Fear of recurrence } \\
\text { Long term treatment side } \\
\text { effects } \\
\text { Memory and concentration } \\
\text { Waiting for results } \\
\text { Children }\end{array}$} \\
\hline 2. Fears/worries & & \\
\hline 3. Poor sleep & $\checkmark$ & \\
\hline 4. Unable to make plans & $\checkmark$ & \\
\hline 5. Nervousness & & \\
\hline 6. Swelling & & \\
\hline 7. Pain/changes in sensation & & \\
\hline 8. Restlessness/unable to relax & & \\
\hline 9. Bowel changes/constipation or diarrhoea & & \\
\hline 10. Washing/dressing & & \\
\hline \multicolumn{3}{|l|}{ Gynaecological cancer ( $n=79$ patients) } \\
\hline 1. Fears/worries & $\checkmark$ & \multirow{9}{*}{$\begin{array}{l}\text { People close to you } \\
\text { Insurance/finance } \\
\text { Genital/gynae concerns } \\
\text { Sexual function } \\
\text { Children } \\
\text { Intimacy } \\
\text { Work/college/school }\end{array}$} \\
\hline 2. Fatigue/tiredness & $\checkmark$ & \\
\hline $\begin{array}{l}\text { 3. Bowel changes/constipation or } \\
\text { diarrhoea }\end{array}$ & $\checkmark$ & \\
\hline 4. Poor sleep & & \\
\hline 5. Nervousness & & \\
\hline 6. Restlessness/unable to relax & & \\
\hline 7. Nausea/vomiting & & \\
\hline 8. Pain/changes in sensation & & \\
\hline 9. Panicky & & \\
\hline
\end{tabular}




\begin{tabular}{|c|c|c|}
\hline 10. Unable to make plans & $\checkmark$ & \\
\hline \multicolumn{3}{|l|}{ Skin cancer $(n=100$ patients) } \\
\hline 1. Fears/worries & $\checkmark$ & \multirow{10}{*}{$\begin{array}{l}\text { Panicking/waiting for } \\
\text { results } \\
\text { Body image } \\
\text { Looking after pets } \\
\text { Loss of independence }\end{array}$} \\
\hline 2. Walking/getting around & $\checkmark$ & \\
\hline 3. Fatigue/tiredness & $\checkmark$ & \\
\hline 4. Poor sleep & $\checkmark$ & \\
\hline 5. Unable to make plans & & \\
\hline 6. Getting to places & & \\
\hline 7. People close to you & $\checkmark$ & \\
\hline 8. Restlessness/unable to relax & & \\
\hline 9. Work/college/school issues & $\checkmark$ & \\
\hline 10. Children & & \\
\hline
\end{tabular}

